\title{
Validation of Stresses with Numerical Method and Analytical Method
}

\author{
Enes Akca \\ International University of Sarajevo, Department of Mechanical Engineering \\ Sarajevo, Bosnia and Herzegovina \\ enesakca@hotmail.com.tr, eakca@ius.edu.ba
}

\begin{abstract}
In this study, the goal is to confirm stresses under kind of loads, with analytical and numerical methods. But each material is drawn in SolidWorks 3D design software, and exported to ANSYS. Also the other purpose is to give information about type of stresses and formulation of each stress with different loads.
\end{abstract}

Keywords:ANSYS, Stress, Shear stress, FEM, Analyticalsolution, Numerical solution

\section{INTRODUCTION}

Stress is defined as the strength of a material per unit area or unit strength. It is the force on a member divided by area, which carries the force, formerly express in $\mathrm{N} / \mathrm{mm}^{2}$ or $\mathrm{MPa}$. And there are types of stresses and component of stresses; normal stress, shear or transversal stress, maximum and minimum principle stresses. Besides, they will be defined in detail in chapter 2 .

As computers have become more and more powerful, people have tended to use numerical approaches to develop theoretical models to predict the effect of whatever is studied. This has improved stress analysis and computer simulations. Numerical methods can potentially provide more accurate solutions since they normally require much less restrictive assumptions. The finite element method is very often used to analyze the stress state of an elastic body with complicated geometries.

The finite element method is capable of providing this information, but the time needed to create such a model is large. In order to reduce the modeling time, a $3 \mathrm{D}$ model created in solid 
modeling software can be used. One such model is provided by SolidWorks. SolidWorks can generate models of three-dimensional members easily. In SolidWorks, the geometry is saved as a file and then it can be transferred from SolidWorks to ANSYS. ANSYS has pioneered the development and application of simulation methods to solve the most challenging product engineering problems. Simulation software enables organizations to confidently predict how their products will operate in the real world [1].

First of all, it should be emphasized that the "numerical approach" is not automatically equivalent to the "approach with use of computer", although we usually use numerical approach to find the solution with use of computers. That is because of the high computer performance incomparable to abilities of human brain. Numerical approach enables solution of a complex problem with a great number of very simple operations. It can be distinguished two main situations when numerical methods are used instead of analytical methods [2];

1. When analytical solution of the mathematically defined problem is possible but it is timeconsuming and the error of approximation we obtain with numerical solution is acceptable. In this case the calculations are mostly made with use of computer because otherwise its highly doubtful if any time is saved. It is also indivually to decide what we mean by "time-consuming analytical solution". In my discipline even very simple mechanical problems are solved numerically simply.

2. When analytical solution is impossible, this means that we have to apply numerical methods in order to find the solution. This does not define that we must do calculations with computer although it usually happens so because of the number of required operations.

Hence in the next chapters, there will be results of both numerical and analytical solutions, also confirmation of 3 tests and one member is just consisting of numerical solution. On account of the fact that it will be proved that ANYS results are reliable if 3 tests are confirmed.

\section{STRESSES}

The purpose is to find the normal and shear stresses acting on any inclined section. For uniaxial load and pure shear, now the transformation relationships that give the stress components for any orientation is need to be derived. This is referred as stress transformation[3].

When an element is rotated from one orientation to another, the stresses acting on the faces of the element are different but they still represent the same state of stress, namely, the stress at the point under consideration.

Axial load

Torsional load in circular shaft

Bending moment and shear force in beam

$$
\begin{aligned}
& \sigma=P / A \\
& \tau=T_{p} / I_{p} \\
& \sigma=M_{y} / I \quad \tau=V Q / I b
\end{aligned}
$$

Plane stress occurs when the material at a point is subjected to two normal stress components $\sigma_{x}$ and $\sigma_{y}$ and a shear stress $\tau_{x y}$. Provided these components are known, then the stress components acting on an element having a different orientation $\theta$ can be determined using the two force equations of equilibrium or the equations of stress transformation [4].

$$
\sigma_{x^{\prime}}=\frac{\sigma_{x}+\sigma_{y}}{2}+\frac{\sigma_{x}-\sigma_{y}}{2} \cos 2 \theta+\tau_{x y} \sin 2 \theta
$$




$$
\tau_{x^{\prime} y^{\prime}}=-\frac{\sigma_{x}-\sigma_{y}}{2} \sin 2 \theta+\tau_{x y} \cos 2 \theta
$$
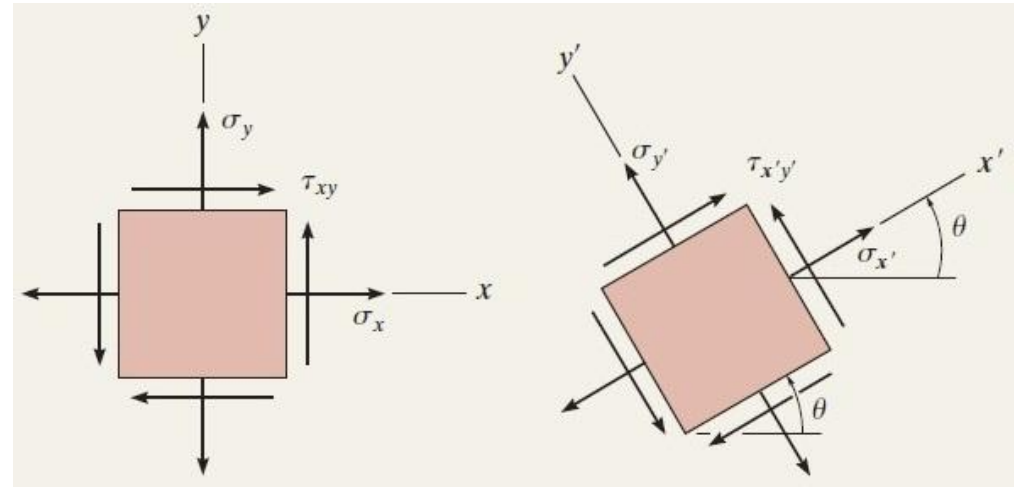

Figure 1: Plane stress

It is important to determine the orientation of the element that produces the maximum principal normal stresses and the maximum in-plane shear stress. Using the stress transformation equations, it is found that no shear stress acts on the planes of principal stress. The principal stresses are

$$
\sigma_{1,2}=\frac{\sigma_{x}+\sigma_{y}}{2} \pm \sqrt{\left(\frac{\sigma_{x}-\sigma_{y}}{2}\right)^{2}+\tau_{x y}^{2}}
$$

The planes of maximum in-plane shear stress are oriented $45^{\circ}$ from this orientation, and on these shear planes there is an associated average normal stress.

$$
\begin{aligned}
& \tau_{\text {in-plane }}=\sqrt{\left(\frac{\sigma_{x}-\sigma_{y}}{2}\right)^{2}+\tau_{x y}^{2}} \\
& \sigma_{\text {avg }}=\frac{\sigma_{x}+\sigma_{y}}{2}
\end{aligned}
$$

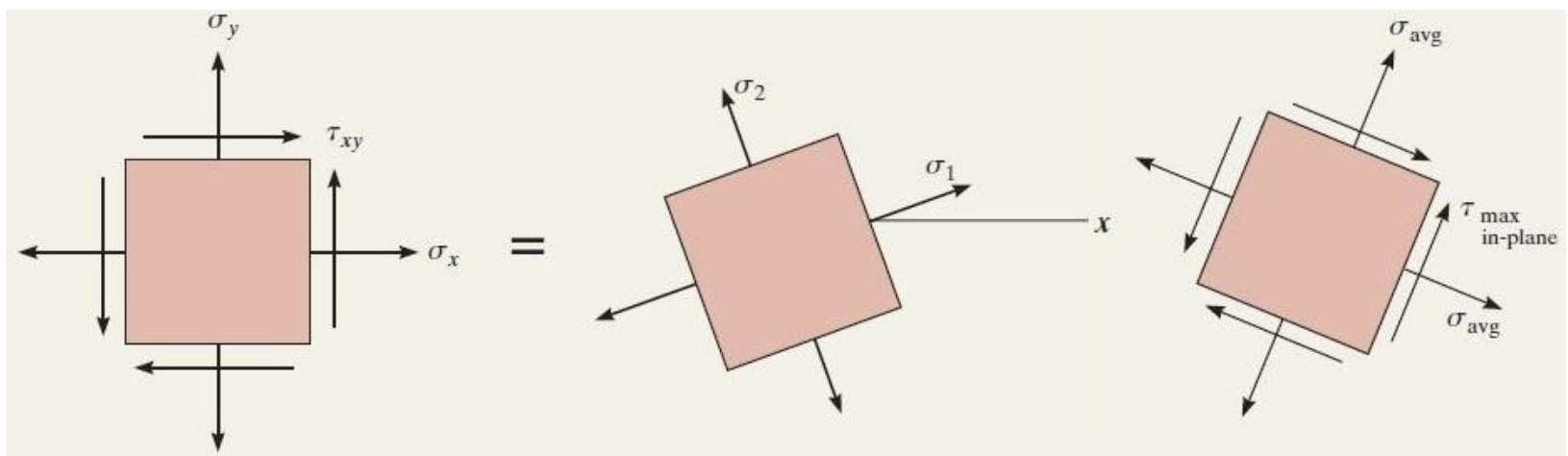

Figure 2: Planes of maximum in-plane shear stress

Mohr's circle provides a semi-graphical method for finding the stress on any plane, the principal normal stresses, and the maximum in-plane shear stress. To draw the circle, the $\sigma$ and $\tau$ axes are established, the center of the circle $C\left[\left(\sigma_{\mathrm{x}}+\sigma_{\mathrm{y}}\right) / 2,0\right]$ and the reference point $A\left(\sigma_{x}, \tau_{x y}\right)$ are plotted. 
The radius $R$ of the circle extends between these two points and is determined from trigonometry [4].

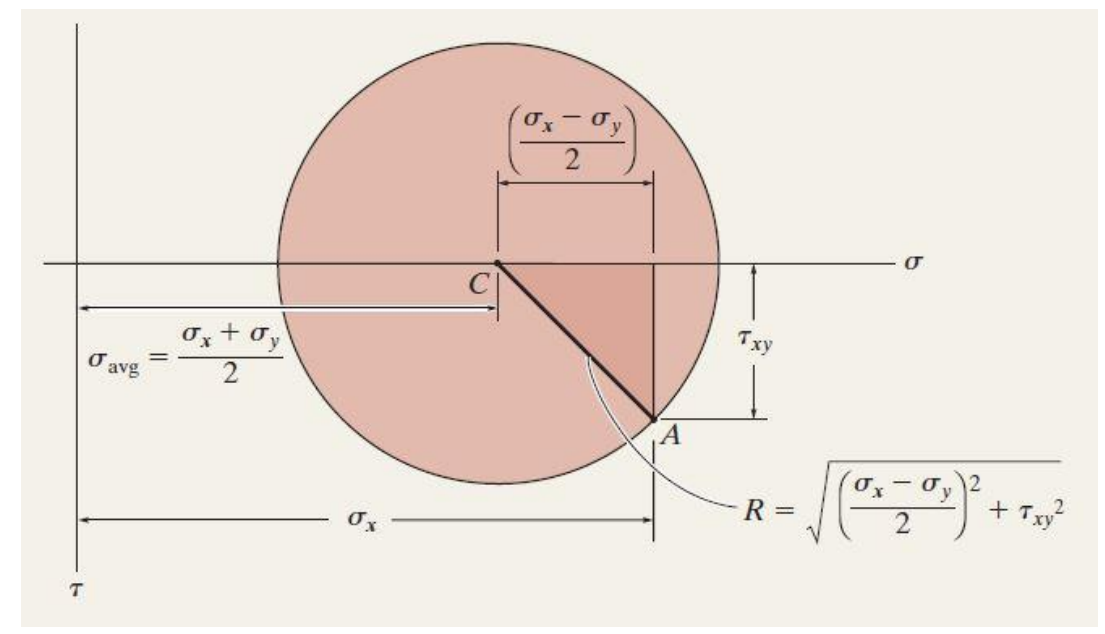

Figure 3: Mohr's circle explanation

If $\sigma_{1}$ and $\sigma_{2}$ are of the same sign, then the absolute maximum shear stress will lie out of plane.

$$
\tau_{\max }^{\max }=\frac{\sigma_{1}}{2}
$$

In the case of plane stress, the absolute maximum shear stress will be equal to the maximum inplane shear stress provided the principal stresses $\sigma_{1}$ and $\sigma_{2}$ have the opposite sign [4].

$$
\tau_{\max }^{\max }=\frac{\sigma_{1}-\sigma_{2}}{2}
$$

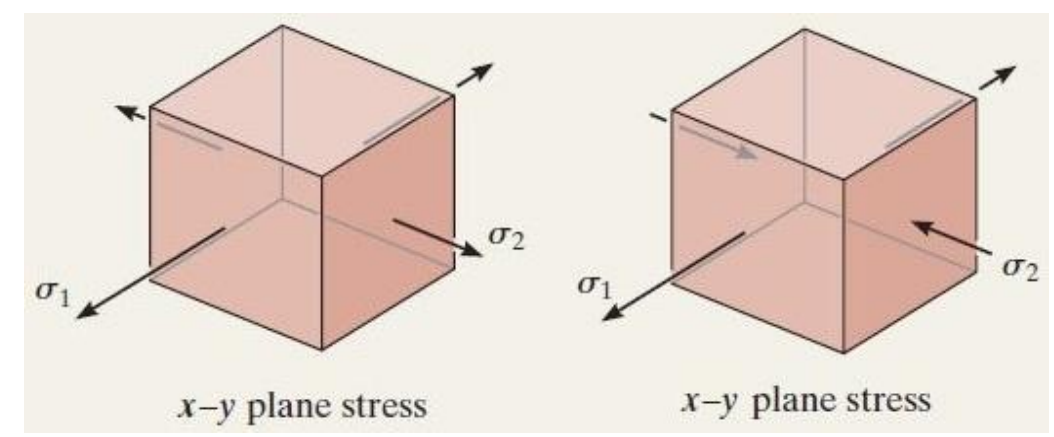

Figure 4: Absolute maximum shear stress

\section{APPLICATION OF STRESSES}

\subsection{Tensile Test}

Tensile testingis a fundamentalmaterials sciencetest in which a sample is subjected to a controlledtensionuntil failure. The results from the test are commonly used to select a material for an application, forquality control, and to predict how a material will react under other types offorces. Properties that are directly measured via a tensile test areultimate tensile strength, maximumelongationand reduction in area.From these measurements the following properties can also be determined:Young's modulus,Poisson's ratio,yield strength, andstrainhardeningcharacteristics. And tension or tensile force will tend to lengthen the member [5]. 


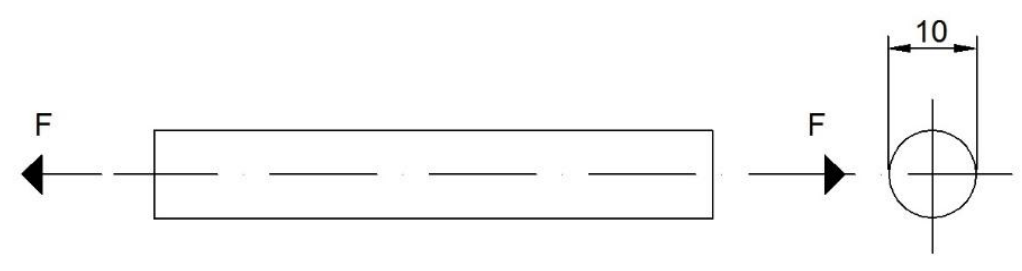

Figure 5: Drawing the bar

A bar that is applied the forces on the both edges of it.

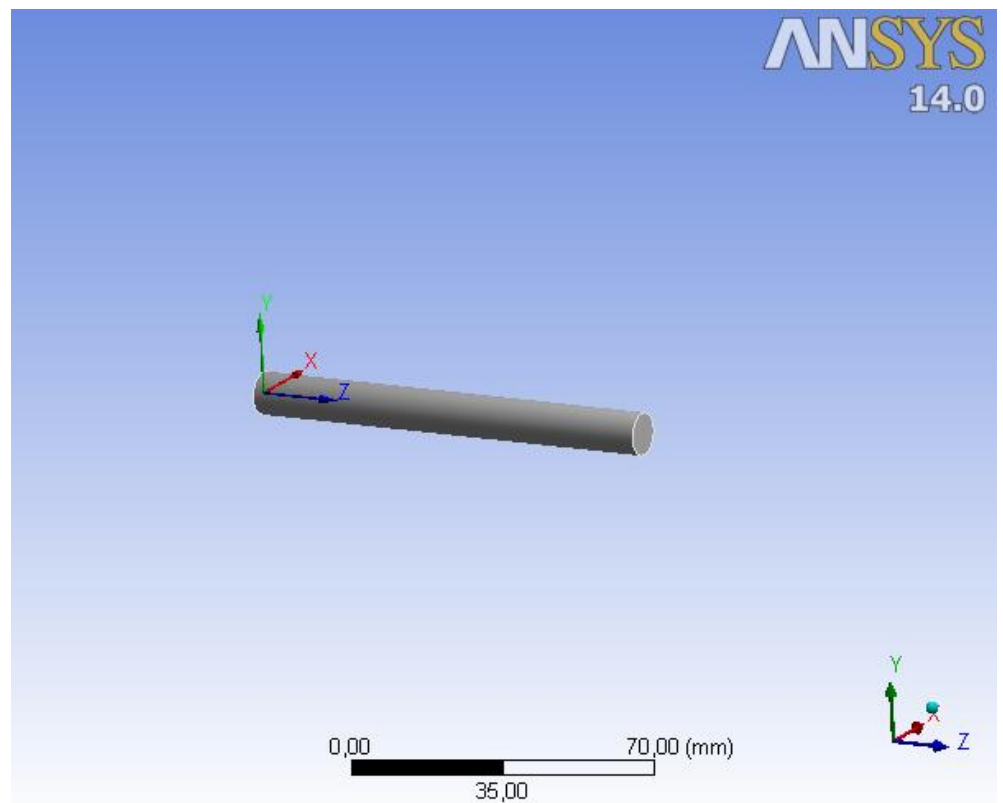

Figure 6: 3D drawing of the bar

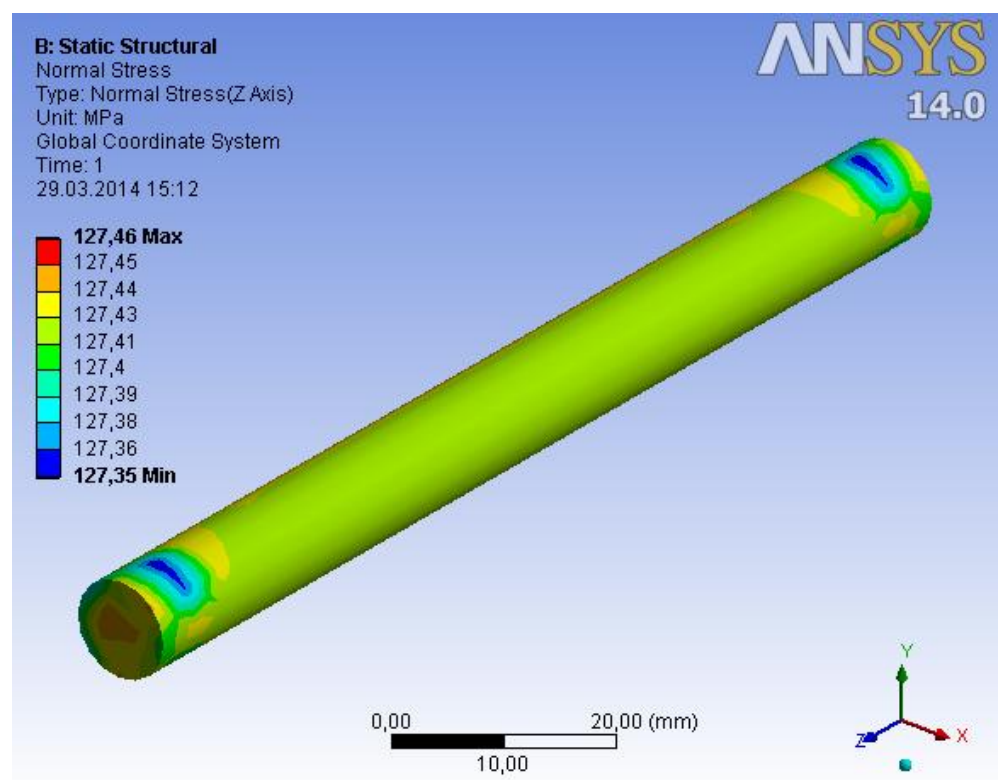

Figure 7: Stress distribution of the bar

Properties and dimensions of the member;

And numerical (ANSYS)result; 


\begin{tabular}{|r|l|}
\hline Material & Alloy steel \\
\hline Tensile Yield Strength $\sigma_{\mathrm{y}}$ & $250 \mathrm{MPa}$ \\
\hline Poisson's Ratio & 0,3 \\
\hline Young's Modulus & $210 \mathrm{GPa}$ \\
\hline Diameter & $10 \mathrm{~mm}$ \\
\hline$F_{\mathrm{n}}$ & $10 \mathrm{kN}$ \\
\hline Normal Stress & $127,46 \mathrm{MPa}$ \\
\hline
\end{tabular}

Result from analytical calculation;

$$
\begin{aligned}
& \sigma=\frac{F}{A} \\
& \sigma=\frac{10 \times 10^{3}}{\frac{\pi *\left(10 * 10^{-3}\right)^{2}}{4}} \\
& \sigma=127 \mathrm{MPa}
\end{aligned}
$$

Hence, the results are close enough to confirm the analytical solution and numerical solution. It is shown in the table below;

$$
\begin{array}{|l|l|}
\hline \text { Analytical Result } & 127 \mathrm{Mpa} \\
\hline \text { Numerical (ANSYS) Result } & 127,46 \mathrm{MPa} \\
\hline
\end{array}
$$

\subsection{Pressure Test}

The pressure is applied inside of a pipe, and it is seen that maximum stress will occur inside of the pipe.

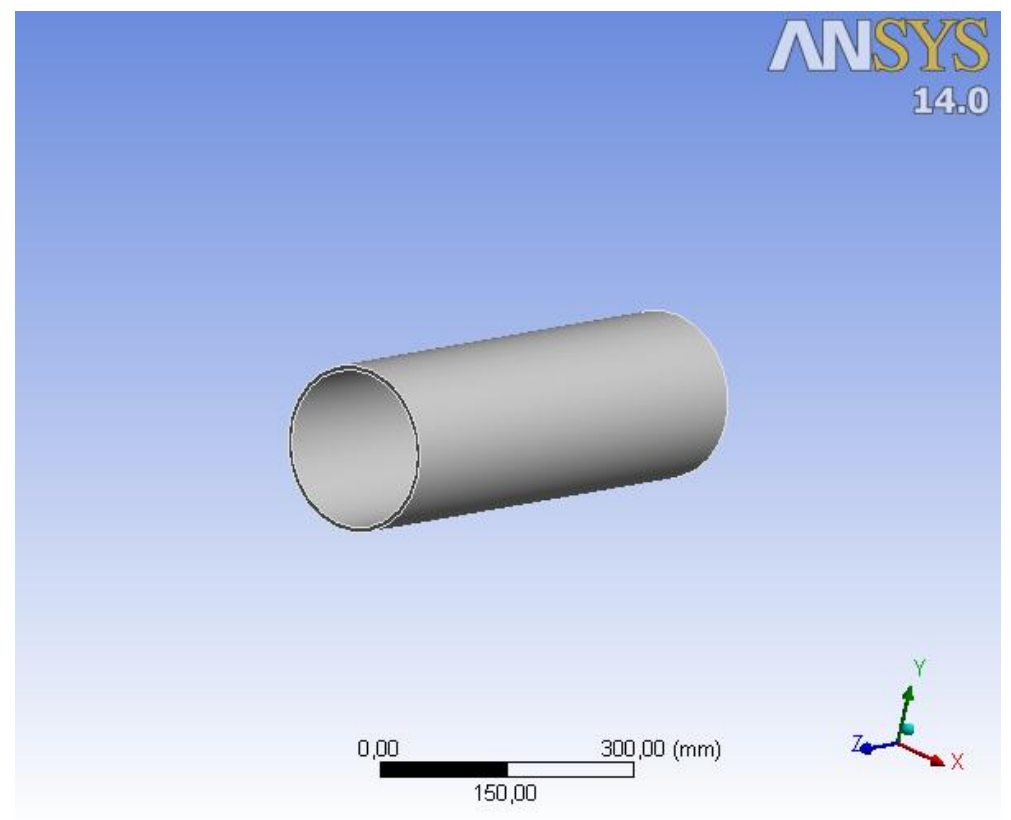

Figure 8: 3D model of the pipe 


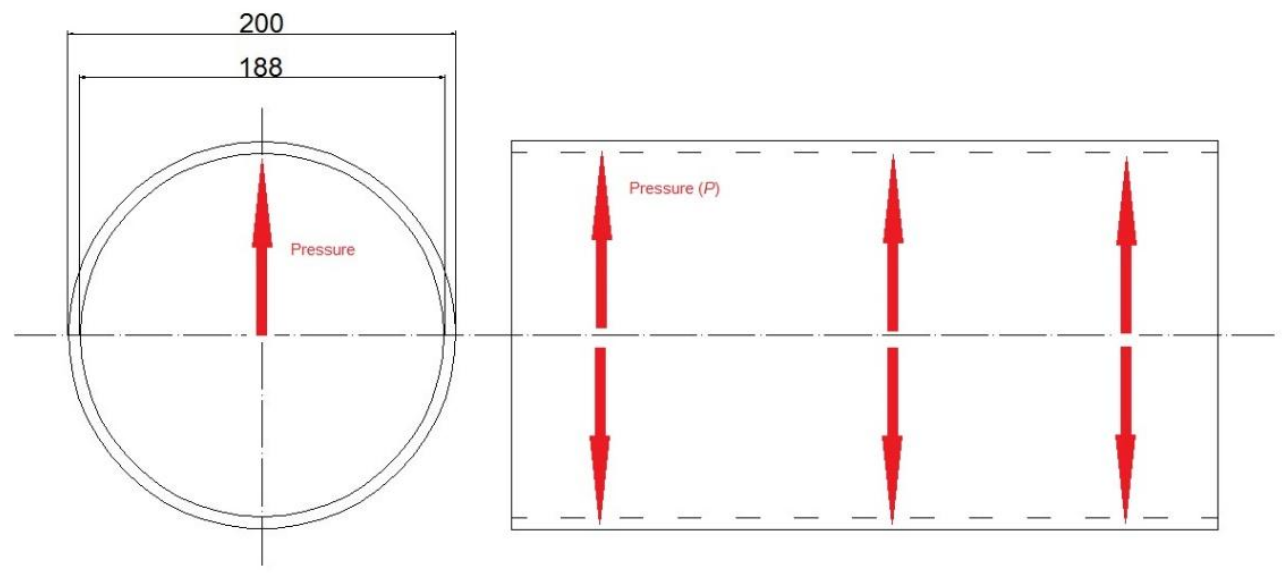

Figure 9: Drawing of the pipe (dimensions are in $\mathrm{mm}$ )

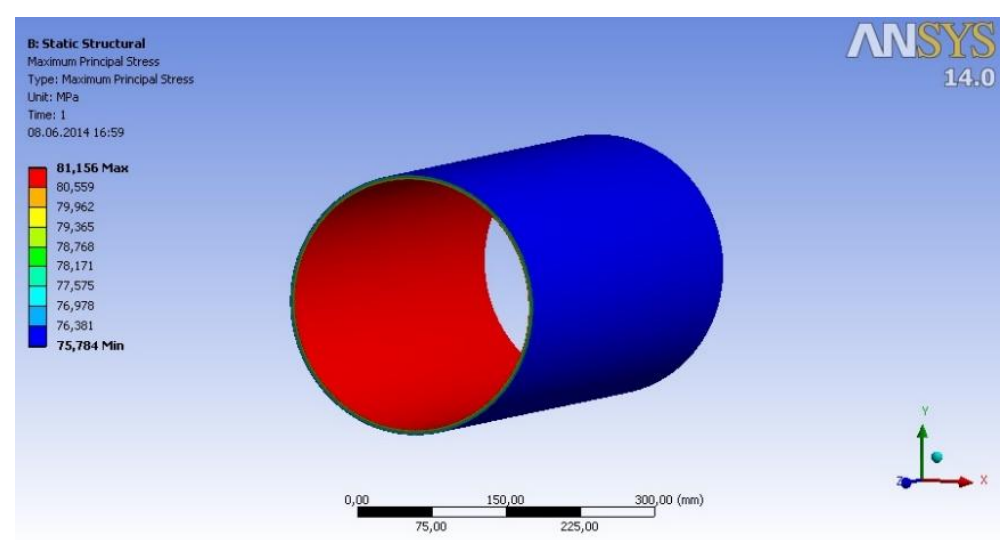

Figure 10: Stress distribution of the pipe

Properties and dimensions of the member;

And numerical (ANSYS)result;

\begin{tabular}{|r|l|}
\hline Material & Alloy steel \\
\hline Tensile Yield Strength $\sigma_{\mathrm{y}}$ & $250 \mathrm{MPa}$ \\
\hline Poisson's Ratio & 0,3 \\
\hline Young's Modulus & $210 \mathrm{GPa}$ \\
\hline Out diameter & $200 \mathrm{~mm}$ \\
\hline Inner diameter & $188 \mathrm{~mm}$ \\
\hline Thickness & $6 \mathrm{~mm}$ \\
\hline Pressure & $5 \mathrm{Mpa}$ \\
\hline Maximum Principal Stress & $81.156 \mathrm{MPa}$ \\
\hline
\end{tabular}

Result from analyticalcalculation;

$$
\begin{aligned}
& O D=200 \mathrm{~mm} \\
& I D=200-12=188 \mathrm{~mm} \\
& R_{i}=\frac{188}{2}=94 \mathrm{~mm}
\end{aligned}
$$




$$
\begin{aligned}
& R_{o}=100 \mathrm{~mm} \\
& t=\frac{200-188}{2}=6 \mathrm{~mm} \\
& \sigma_{t}=\frac{P \times R i}{t} \leq \sigma_{t, \text { max }} \\
& \sigma_{t}=\frac{5 \times 94}{6} \leq \sigma_{t, \text { max }} \\
& \sigma_{t, \text { max }}=80 \mathrm{MPa}
\end{aligned}
$$

Hence, the results are close enough to confirm the analytical solution and numerical solution (ANSYS). It is shown in the table below;

$$
\begin{array}{|l|l|}
\hline \text { Analytical result } & 80 \mathrm{MPa} \\
\hline \text { Numerical (ANSYS) result } & 81.156 \mathrm{MPa} \\
\hline
\end{array}
$$

\subsection{Combined Load}

Force $\mathrm{A}, \mathrm{B}$ and $\mathrm{C}$ are applied to the surface of the $\mathrm{L}$ and on the other surface of the $\mathrm{L}$ is fixed support with $\mathrm{D}$ that is shown in figure 11 . Hence the purpose is to calculate the stresses on different forces [6].

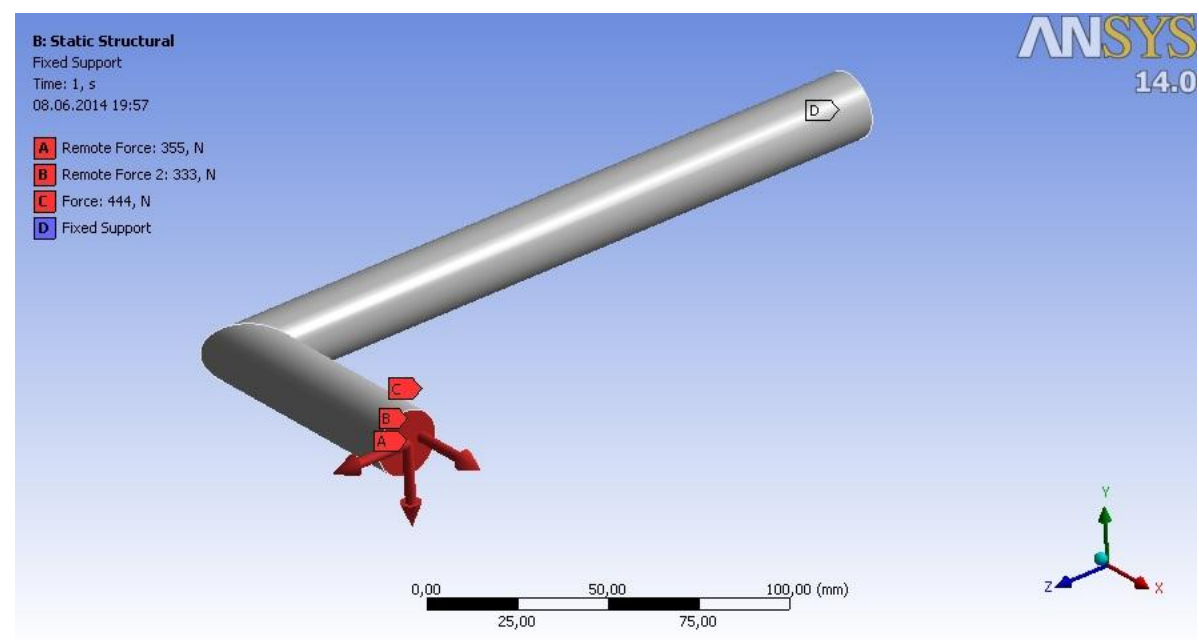

Figure 11: Forces on the $\mathrm{L}$

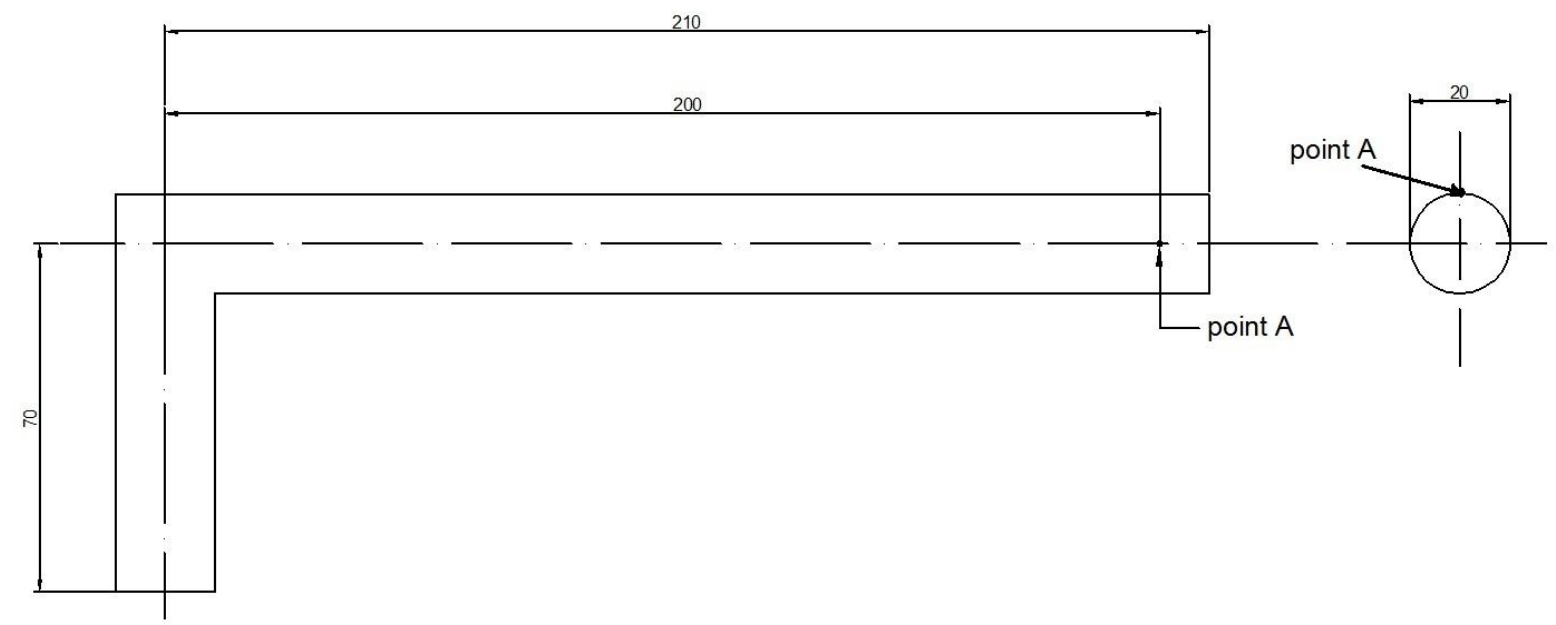


Figure 12: Dimension and the point of $\mathrm{L}$ (dimensions are in $\mathrm{mm}$ )

Properties of the member;

\begin{tabular}{|r|l|}
\hline Material & Alloy steel \\
\hline Tensile Yield Strength $\sigma_{\mathrm{y}}$ & $250 \mathrm{MPa}$ \\
\hline Poisson's Ratio & 0,3 \\
\hline Young's Modulus & $210 \mathrm{GPa}$ \\
\hline Diameter & $20 \mathrm{~mm}$ \\
\hline Force A & $355 \mathrm{~N}$ \\
\hline Force B & $333 \mathrm{~N}$ \\
\hline Force C & $444 \mathrm{~N}$ \\
\hline
\end{tabular}

All the calculations are made by manually in below, and each of it represents types of moment and type of forces that includes axial forces, transversal forces in $3 \mathrm{D}$, torsion and bending moment in 2D.

$$
\begin{array}{ll}
\mathrm{F}_{\mathrm{x}}=333 \mathrm{~N} & \text { (axial tension) } \\
\mathrm{F}_{\mathrm{y}}=355 \mathrm{~N} & \text { (transverse shear in y direction) } \\
\mathrm{F}_{\mathrm{z}}=-444 \mathrm{~N} & \text { (transverse shear in }-\mathrm{z} \text { direction) } \\
\mathrm{M}_{\mathrm{x}}=-\left(7 \times 10^{-2}\right) \times 355=-24,85 \mathrm{Nm} & \text { (torsion } \mathrm{x}-\mathrm{axis}) \\
\mathrm{M}_{\mathrm{y}}=333 \times 7 \times 10^{-2}-444 \times 20 \times 10^{-2}=-65,5 \mathrm{Nm} & \text { (bending moment y-axis) } \\
\mathrm{M}_{\mathrm{z}}=-355 \times 20 \times 10^{-2}=-71 \mathrm{Nm} & \text { (bending moment z-axis) } \\
A=\frac{\pi x d^{2}}{4}=3,14 \times 10^{-4} \mathrm{~m}^{2} & \text { (surface area) } \\
I=\frac{\pi x r^{4}}{4}=7,854 \times 10^{-9} \mathrm{~m}^{4} & \text { (moment of inertia) } \\
J=\frac{\pi \times r^{4}}{2}=1,57 \times 10^{-8} \mathrm{~m}^{4} & \text { (polar moment of inertia) } \\
\sigma=\frac{F}{A}=\frac{333}{3,14 \times 10^{-4}}=1,06 \mathrm{MPa} & \text { (Axial) } \\
\tau_{t o r}=\frac{M_{x} r}{J}=\frac{24,85 \times 0,01}{1,57 \times 10^{-8}}=15,82 \mathrm{MPa} & \text { (Torque) } \\
\tau_{x y}=\frac{4 \mathrm{~V}}{3 \mathrm{~A}}=\frac{4 \times 444}{3,14 \times 3 \times 10^{-4}}=1,88 \mathrm{MPa} & \text { (Transversal shear) } \\
\sigma=\frac{M_{z} y}{I}=\frac{71 \times 0,01}{7,854 \times 10^{-9}}=90,4 \mathrm{MPa} & \text { (Bending) }
\end{array}
$$

Thus, with those calculation, it will be calculated normal stress, shear stress, maximum principle stress, minimum principle stress in the next subtitles, and also the calculation of those stresses is explained in $2^{\text {nd }}$ chapter as theory. 


\subsubsection{Normal Stress}

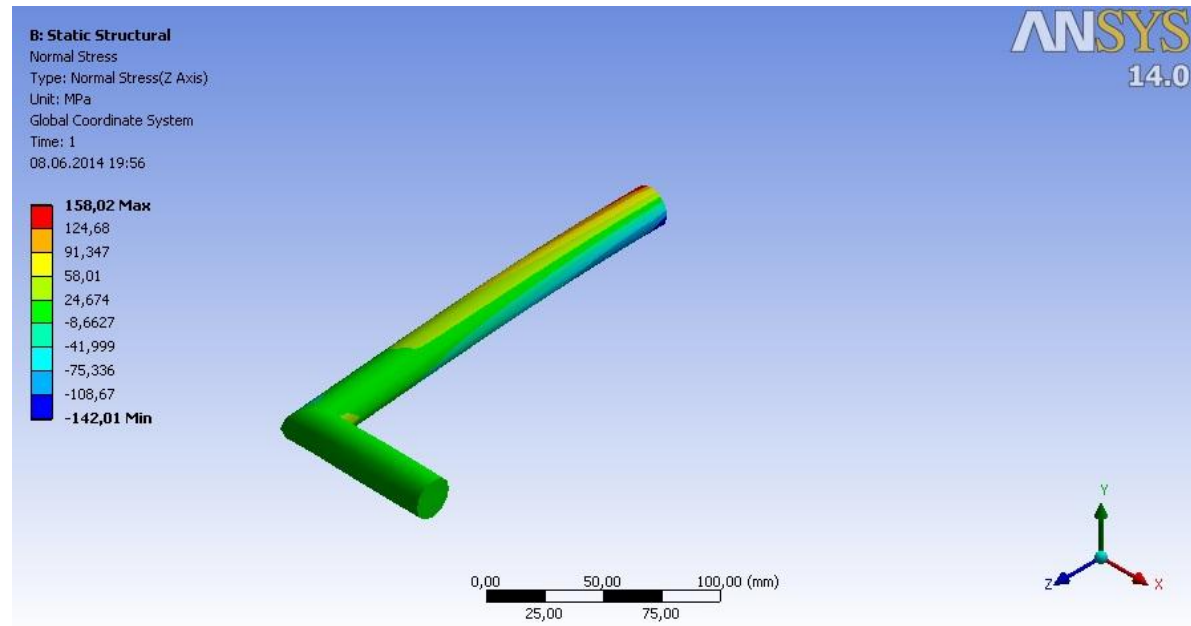

Figure 13: Normal stress

$$
\begin{aligned}
& \sigma_{x}=1,06+90,4=91,46 \mathrm{MPa} \\
& \tau=0
\end{aligned}
$$

A stress is defined as the load divided by the area. For a normal stress, it is all loads perpendicular to the surface.

\subsubsection{Shear Stress}

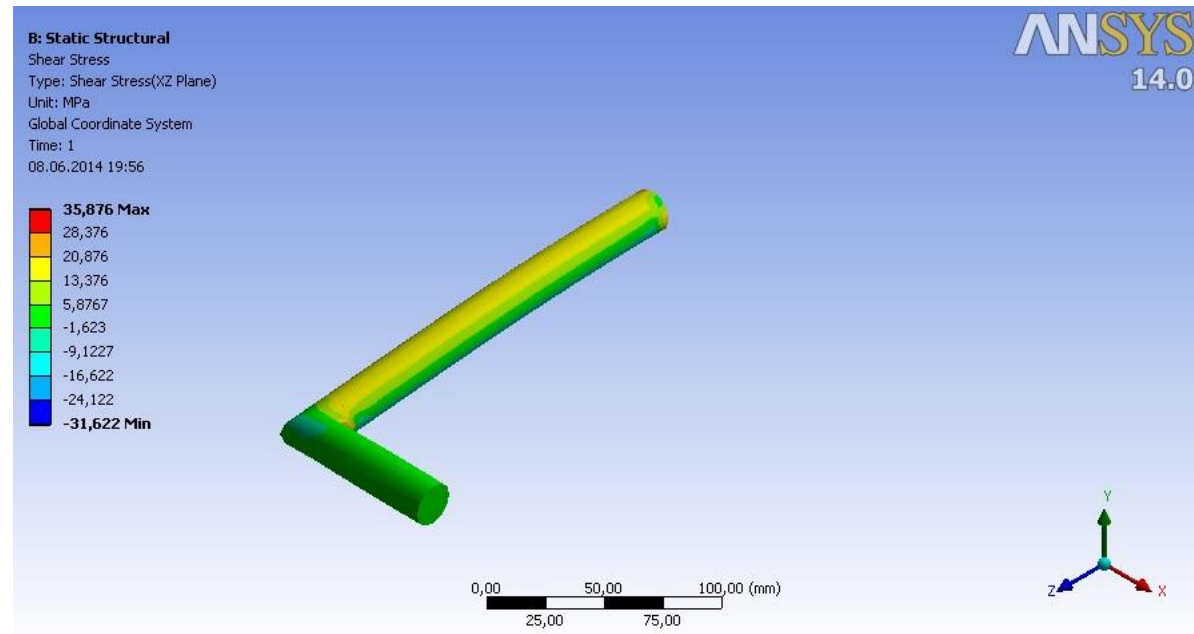

Figure 14: Shear stress

$$
\begin{aligned}
& \sigma=91,46 \mathrm{MPa} \\
& \tau=\tau_{x y}+\tau_{\text {tor }}=1,88+15,82=17,7 \mathrm{MPa}
\end{aligned}
$$

Shear stress is a stress state where the stress is parallel to the surface of the material, as opposed to normal stress when the stress is vertical to the surface. 


\subsubsection{Maximum Principle Stress}

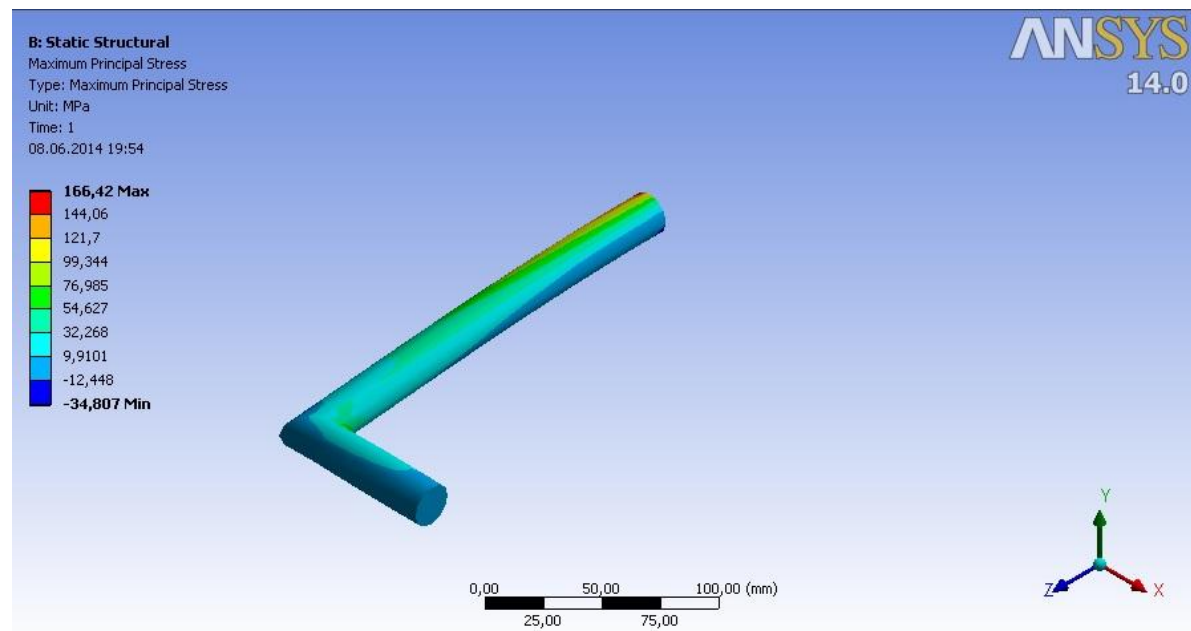

Figure 15: Max principle stress

$$
\begin{aligned}
& R=\sqrt{(91,46 / 2)^{2}+17,7}=45,92 \\
& \sigma_{l}=\frac{91,46}{2}+45,92=91,65 \mathrm{MPa}
\end{aligned}
$$

\subsubsection{Minimum Principle Stress}

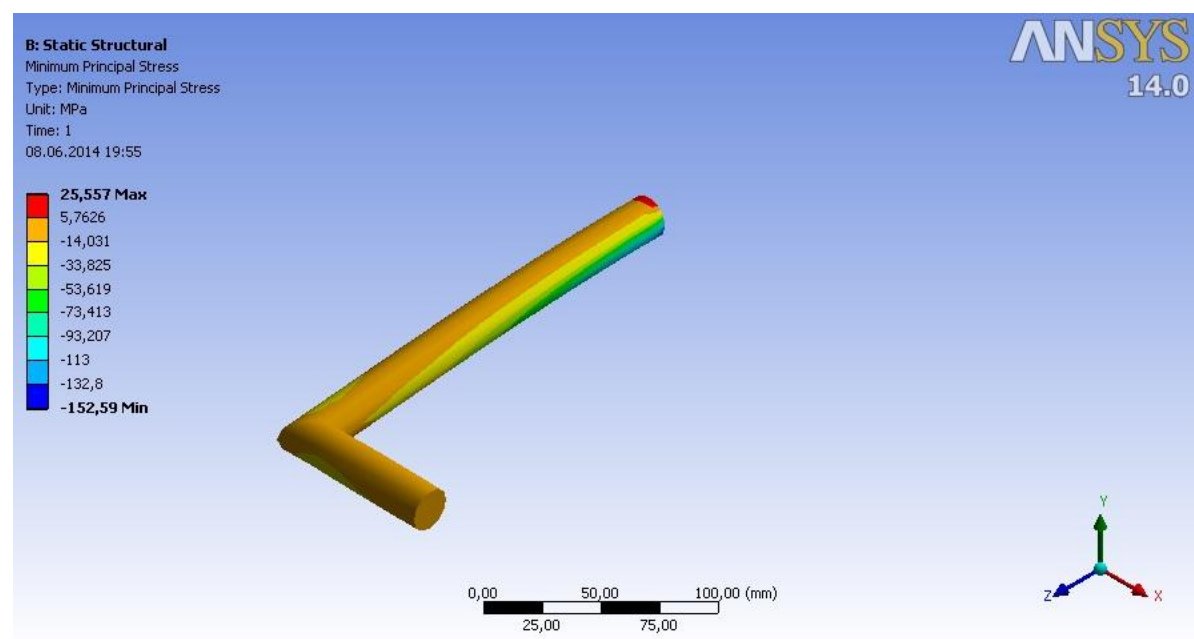

Figure 16: Min principle stress

$$
\begin{aligned}
& R=\sqrt{(91,46 / 2)^{2}+17,7}=45,92 \\
& \sigma_{2}=\frac{91,46}{2}-45,92=-0,19 \mathrm{MPa}
\end{aligned}
$$

\subsubsection{Results}

\begin{tabular}{|l|l|}
\multicolumn{2}{|c|}{ Analytical (manual) Results } \\
\hline Normal Stress & $91,46 \mathrm{Mpa}$ \\
\hline Shear Stress & $17,7 \mathrm{MPa}$ \\
\hline Max Principle Stress & $91,65 \mathrm{MPa}$ \\
\hline
\end{tabular}




\begin{tabular}{|l|l|}
\hline \multicolumn{2}{|c|}{ Numerical (Ansys) Results } \\
\hline Normal Stress & $91,347 \mathrm{Mpa}$ \\
\hline Shear Stress & $13<\tau<20 \mathrm{MPa}$ \\
\hline Max Principle Stress & $76<\sigma_{1}<99 \mathrm{MPa}$ \\
\hline Min Principle Stress & $-14<\sigma_{2}<5 \mathrm{MPa}$ \\
\hline
\end{tabular}

Hence, results which including analytical and numerical are compared, and it is confirmed in the tables above.

The mesh size must depend on the element size and it is an important topic in a finite element method because of its relationship to accuracy. As the element size increases, it is seen that the results become more accurate and almost constant in table above [7].

\section{CONCLUSION}

Finite element modelling of the members in some forces was examined in detail in chapter 3 , and it is confirmed that the manual solutions and analytical solutions are verified. Hence it is proven that the software (ANSYS) is reliable, and it is considered that ANSYS results are true since the results approach each other and it is nearly constant. Also, in the chapter 4, it is tested only with numerical solution, it is seen that results are nearly constant and more accurate when element sizing is 40, 50 and 60 for both maximum principle stresses and minimum principle stresses.

\section{REFERENCES}

1. M.J.Fagan. Finite Element Analysis-Theory and Practices, Longman Group UK Ltd, 1992.

2. W. O. Jolley, J .J. Rencis, and H. T. Grandin, Jr., "A Module for Teaching Fundamentals of Finite Element, Theory and Practice Using Elementary Mechanics of Materials", Proceedings of the 2003 American, Society for Engineering Education Annual Conference \& Exposition, Nashville, Tennessee, June 2003.

3. B.J. Hamrock, B. Jacobson, S. R. Schmid, "Fundamentals of Machine Elements", 1999.

4. R. C. Hibbeler, "Mechanics of Materials", $8^{\text {th }}$ edition in SI units, Prentice-Hall, 2011.

5. Budynas, R. G., \& Nisbett, J. K., "Shigley's Mechanical Engineering Design”, New York: McGraw-Hill, 2008.

6. V.B.Bhandari, "Design of Machine Elements", Tata McGraw Hill, New Delhi, 2010.

7. R. L. Norton, "Machine Design: An Integrated Approach", $2^{\text {nd }}$ edition, Prentice-Hall,New Jersey, 2000. 